\title{
EDITORIAL
}

\section{CONGRESO SOBRE INVESTIGACIÓN EN DIDÁCTICA DE LAS CIENCIAS}

\author{
LA INVESTIGACIÓN EN DIDÁCTICA DE LAS CIENCIAS. \\ UN COMPROMISO CON LA SOCIEDAD DEL CONOCIMIENTO
}

Girona, 9, 10, 11 y 12 de septiembre de 2013

Del 9 al 12 de septiembre de 2013 se celebrará la 9. a edición del Congreso Internacional sobre Investigación en la Didáctica de las Ciencias (<www.congresoenseciencias.com>), organizado por la revista Enseñanza de las Ciencias. En esta ocasión, el congreso se celebrará en la ciudad de Girona (España).

Bajo el lema «La investigación en didáctica de las ciencias. Un compromiso con la sociedad del conocimiento», el congreso pretende reforzar la voluntad de la didáctica de las ciencias de tener una fuerte implicación en el contexto social en el que vivimos. Ello supone realizar un análisis profundo y riguroso de las claves que explican la sociedad del conocimiento para reforzar el espacio de la didáctica de las ciencias como un agente de cambio.

Por este motivo, las aportaciones científicas del congreso se focalizan en las investigaciones respecto a los retos que presenta la sociedad del conocimiento al sistema educativo, al perfil competencial del profesorado y a las competencias que el alumnado debe adquirir. Se propone tratar los siguientes ámbitos temáticos preferentes: Educación científica en contextos formales, Educación científica en contextos no formales, Educación científica en entornos virtuales, Formación inicial y permanente del profesorado, Educación ambiental y educación para la sostenibilidad, Historia y naturaleza de la ciencia, Aprendizaje científico. Factores cognitivos, emocionales y sociales, Lenguaje y argumentación, Evaluación de programas y aprendizajes, Enfoques de la educación científica en contexto, Complejidad e interdisciplinariedad, Diseño, implementación y evaluación de propuestas didácticas, Educación científica y diversidad.

El comité organizador del congreso es sensible al escenario socioeconómico que estamos viviendo, por ello plantea un encuentro que, sin renunciar a una alta calidad científica y un óptimo clima social, tenga como objetivos la austeridad en la gestión y la máxima participación de las personas que formamos el área. Apostamos porque Girona 2013 sea un encuentro de referencia del colectivo de investigación en Didáctica de las Ciencias del área iberoamericana y animamos a todos los investigadores a una participación activa. Recordamos que la página web propone un espacio de registro personal que facilitará el conocimiento inmediato de las novedades que se vayan produciendo en relación con aspectos organizativos y científicos (<www.congresoenseciencias.com>). 


\section{Fechas de interés}

\begin{tabular}{|l|l|l|l|l|l|l|}
\hline Plazo & $\begin{array}{l}\text { 15 octubre 12 } \\
7 \text { enero 13 }\end{array}$ & $\begin{array}{c}\text { 14 enero } \\
8 \text { marzo 12 }\end{array}$ & $\begin{array}{c}9 \text {-15 marzo } \\
2013\end{array}$ & $\begin{array}{c}\text { Hasta } \\
1 \text { mayo 13 }\end{array}$ & $\begin{array}{c}\text { Hasta } \\
31 \text { mayo 13 }\end{array}$ & $\begin{array}{c}1 \text { junio } \\
15 \text { julio 13 }\end{array}$ \\
\hline Acción & $\begin{array}{l}\text { Envío de } \\
\text { propuestas de } \\
\text { comunicación } \\
\text { y simposio }\end{array}$ & $\begin{array}{l}\text { Evaluación de } \\
\text { propuestas }\end{array}$ & $\begin{array}{l}\text { Notificación } \\
\text { del resultado } \\
\text { de la } \\
\text { evaluación }\end{array}$ & $\begin{array}{l}\text { Envío de texto } \\
\text { completo de } \\
\text { las propuestas }\end{array}$ & $\begin{array}{l}\text { Inscripción } \\
\text { tarifa reducida }\end{array}$ & $\begin{array}{l}\text { Inscripción } \\
\text { tarifa ordinaria }\end{array}$ \\
\hline Responsable & Primer autor & $\begin{array}{l}\text { Comité } \\
\text { Científico }\end{array}$ & $\begin{array}{l}\text { Secretaría } \\
\text { Ejecutiva }\end{array}$ & Primer autor & Asistentes & Asistentes \\
\hline
\end{tabular}

